\title{
MOBILITY AND FUNCTIONAL INDEPENDENCE AFTER INPATIENT STROKE REHABILITATION
}

Marius Panavas, PT, Silvija Reimerytè, PT, Donatas Svirskis, PT, Vita Sinkevičienè, PT, Sigitas Streikus, PT Jūratè Kesienė, MD. Centre of Rehabilitation, Physical and Sports Medicine, Vilnius University Hospital, Santaros Klinikos

Introduction: Stroke is a medical condition in which poor blood flow to the brain results in cell death. Each year thousands of people suffer from this disease in Lithuania. It is important to evaluate and analize patients functional status before and after rehabilitation, as analysis of the outcomes and its determinants allows us to improve rehabilitation program.

Aim: The aim of this study was to analyze changes in mobility and functional independence of people who suffered from the stroke after inpatient rehabilitation program.

Materials and methods: 60 patients after stroke from VUH Santaros Clinics Centre of Rehabilitation, Physical and Sports Medicine in-patient unit where included in this study. All they were examined before and after inpatient stroke rehabilitation program. Main mobility functions (rolling in bed, sitting up, transferring, walking or moving with wheelchair and climbing stairs) were evaluated and Barthel index was used to evaluate patient functional independence. Data analysis was performed using "Mircrosoft Office Excel 2016" and "SPSS" applications.

Results: All 60 stroke patients ( 23 female and 37 men) mobility level has increased. Patients after rehabilitation mostly improved in rolling in bed, sitting up and transferring (Chart 1), less progress was observed in walking and climbing stairs functions (analysis of changes in different mobility functions will be presented) $(p<0.05)$ (Chart 2). Barthel index after rehabilitation increased from $13,66 \pm 15,34$ to $53,08 \pm 25,52(p<0,05)$ (Chart 3).

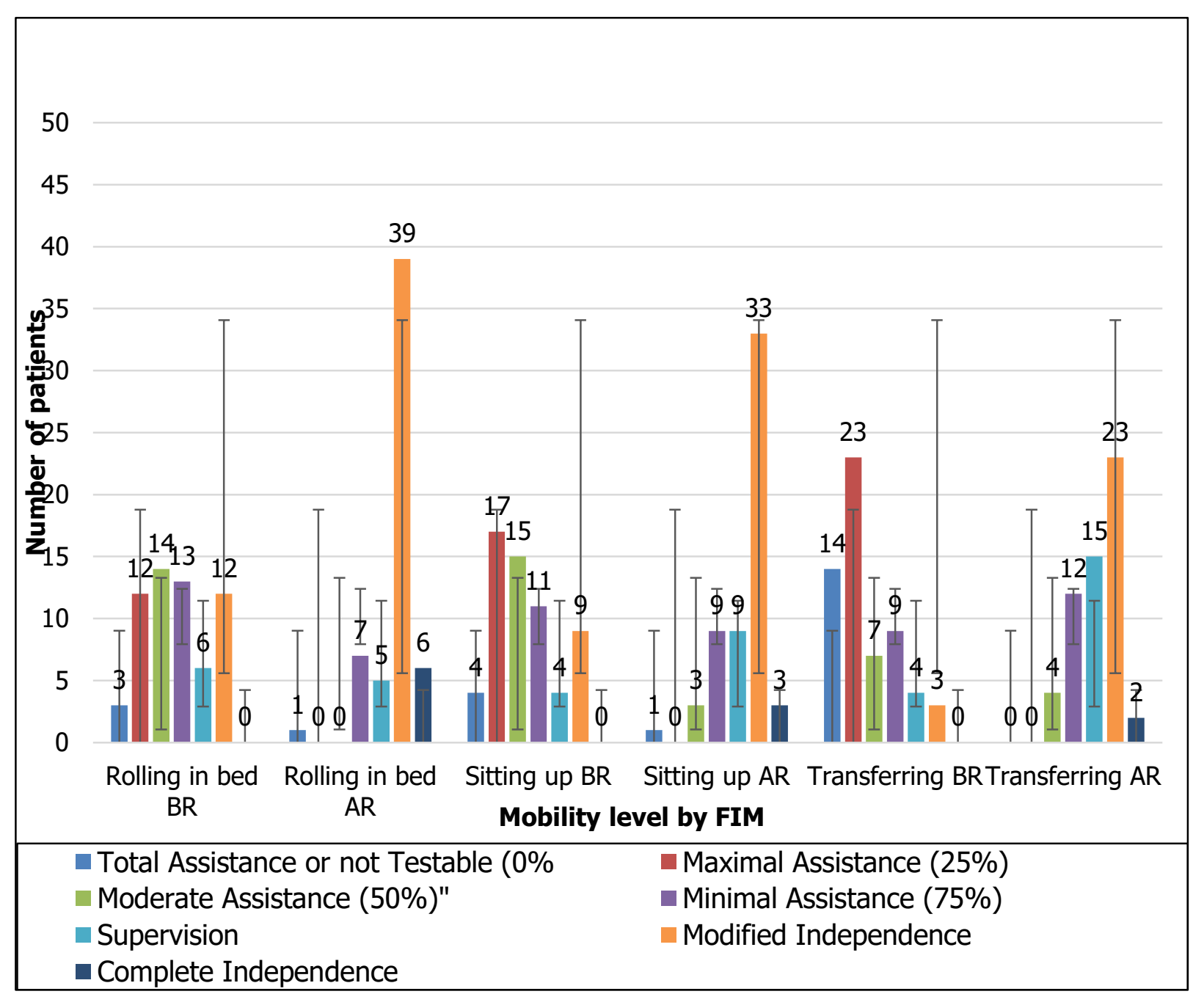

Chart 1. Mobility level before and after rehabilitation.

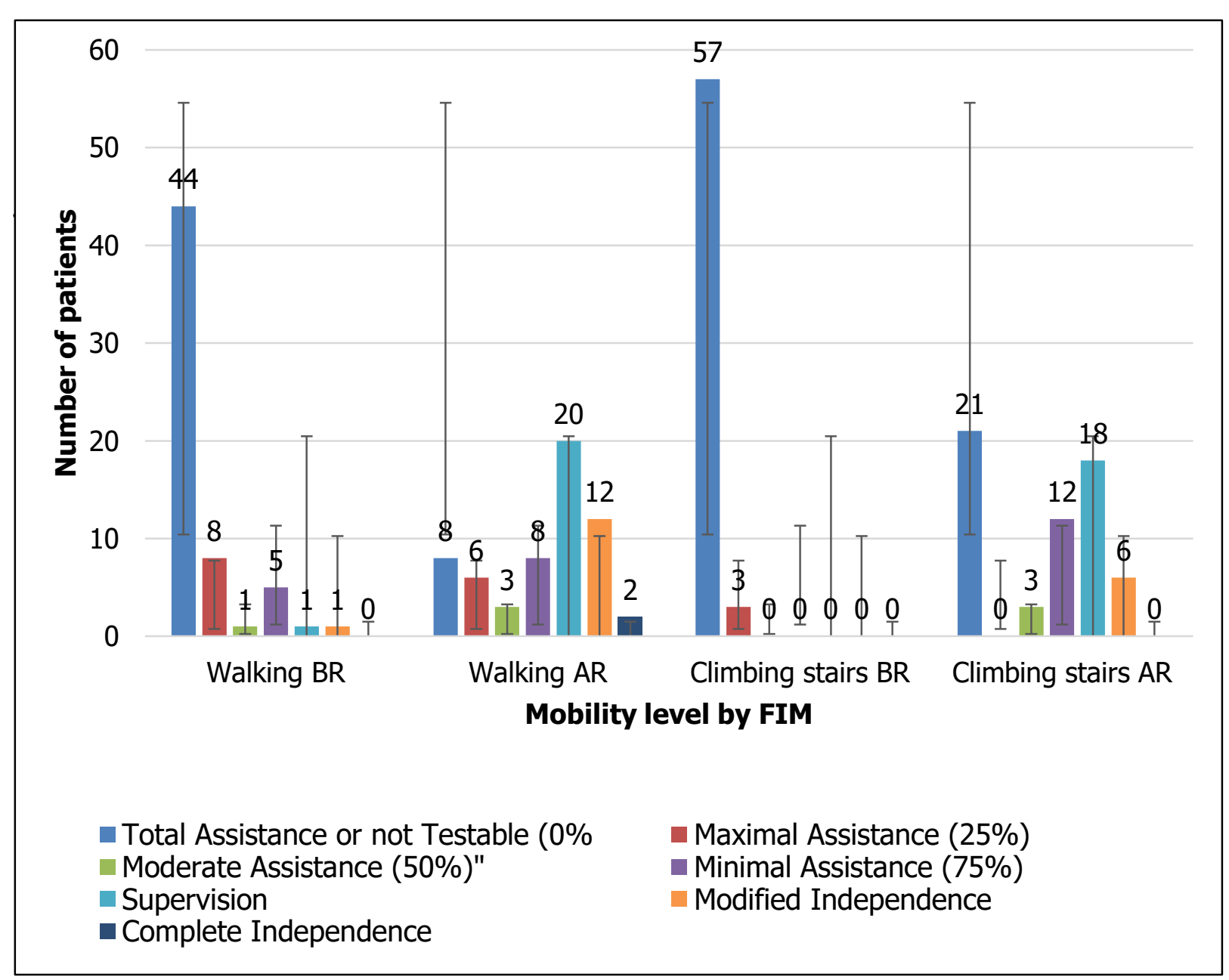

Chart 2. Mobility level before and after rehabilitation.

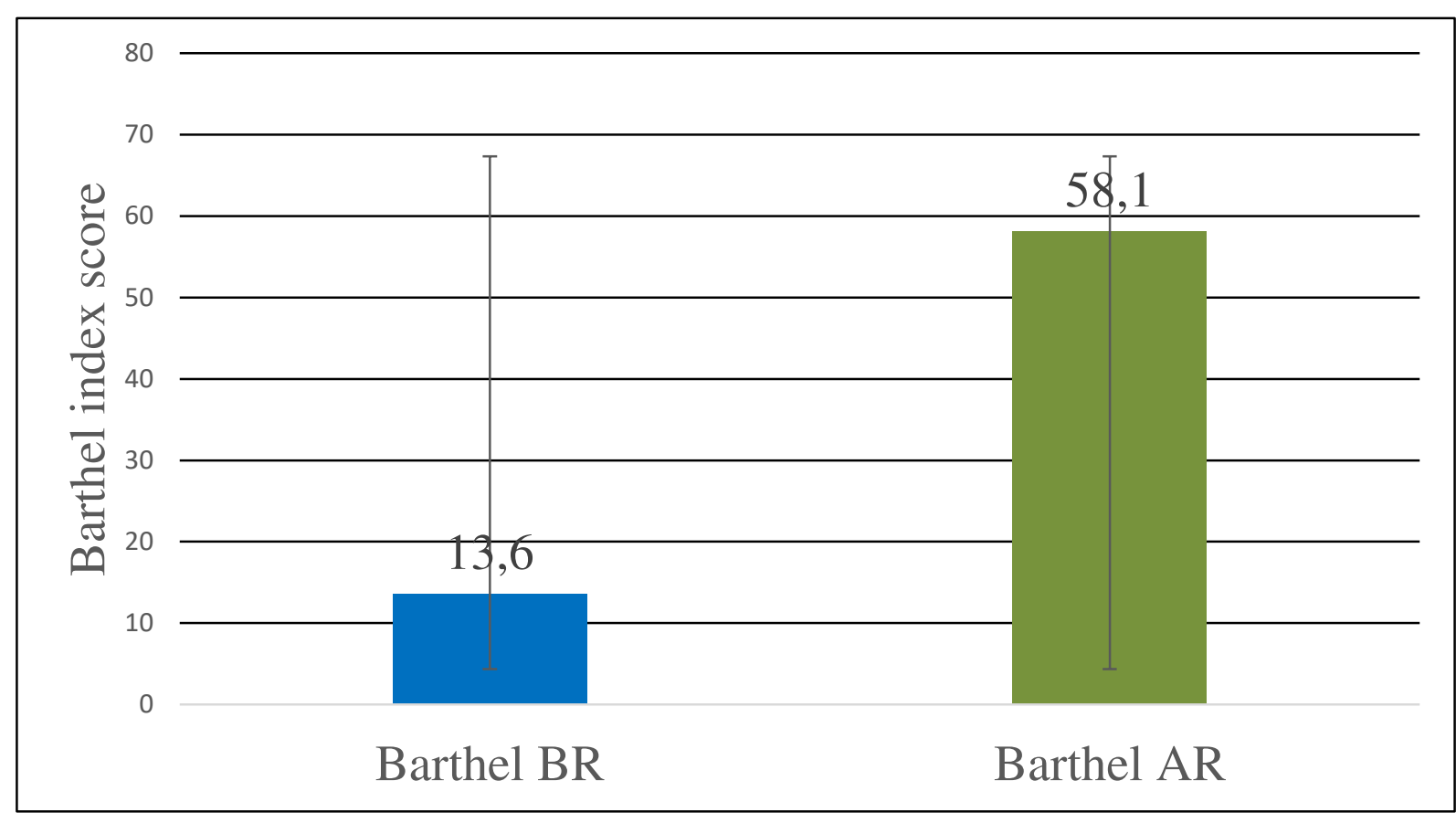

Chart 3. Barthel index before and after rehabilitation.

Conclusions: Study has shown that after rehabilitation patients improved their mobility skills and functional independence has also increased and was higher in patients who regained skills in walking and stairs climbing. 